NOTE

\title{
Genetically different Atlantic herring Clupea harengus spawning waves
}

\author{
Arran A. McPherson ${ }^{1,3, *}$, Robert L. Stephenson ${ }^{2}$, Christopher T. Taggart ${ }^{1}$ \\ ${ }^{1}$ Department of Oceanography, Dalhousie University, Halifax, Nova Scotia B3H 4J1, Canada \\ ${ }^{2}$ St. Andrews Biological Station, Department of Fisheries and Oceans, 531 Brandy Cove Road, St. Andrews, New Brunswick E5B 2L9, Canada \\ ${ }^{3}$ Present address: Bedford Institute of Oceanography, Department of Fisheries and Oceans, 1 Challenger Drive, Dartmouth, \\ Nova Scotia B2Y 4A2, Canada
}

\begin{abstract}
Putative spawning waves of Atlantic herring Clupea harengus were collected from 4 locations and genetically compared using 9 microsatellite loci. Shelf-scale (100s $\mathrm{km})$ spatial differences were measured $\left(\max F_{\mathrm{ST}}=0.01\right.$, $\mathrm{p}<0.001)$ and 1 sub-annual temporal difference $\left(F_{\mathrm{ST}}=0.0058\right.$, $\mathrm{p}=0.001$ ) was revealed between spawning fish (predominantly comprising the same year-class) collected, $6 \mathrm{~d}$ apart, from the same location (Devastation Shoal, coastal Nova Scotia). Herring in the second spawning collection at Devastation Shoal had a greater average length-at-age within the year-class ( $t$-test, $\mathrm{p}<0.001)$. The genetic and morphometric differences between the Devastation Shoal collections are assumed to reflect a replacement period of spawning fish of approximately $6 \mathrm{~d}$ or less (at least at this location). We offer 3 explanations to account for the observations: (1) genetically distinct sympatric subpopulations or spawning waves; (2) sub-annual (d) genetic patchiness; and (3) transient use of spawning grounds which may indicate that the assumption of philopatry (natal spawning-site fidelity) in herring is invalid.
\end{abstract}

KEY WORDS: Spawning wave $\cdot$ Atlantic herring $\cdot$ Sympatric populations $\cdot$ Genetic

Resale or republication not permitted without written consent of the publisher

Small-scale, seemingly unpatterned, genetic heterogeneity among and within local populations of marine organisms (Johnson \& Black 1982, Hedgecock 1994, Larson \& Julian 1999, Chapman et al. 1999) has been observed when the genetic composition of samples (assumed to be representative of populations) varies as much over time at 1 location as over large distances (Purcell et al. 1996, David et al. 1997). This can occur even when the sampling strategy is considered optimal (e.g. spawning Atlantic herring Clupea harengus collected on the spawning grounds; Kornfield et al. 1982).

*Email: mcphersona@mar.dfo-mpo.gc.ca
There are a number of so-called 'adaptive' and chance-related processes that may generate the apparent genetic heterogeneity. It has been proposed (e.g. Hedgecock 1994; sweepstakes hypothesis) that temporal genetic variation in marine organisms may result from a large variance in reproductive success among adults such that resulting year-classes comprise the progeny of a small proportion of the spawning population (i.e. not representative of the entire population). The consequences may be: a reduction in genetic variation among recruits within a year-class; differences between the genetic composition of recruits and the spawning population presumed (in its entirety) to have produced them; and subsequent differences in the genetic composition of the recruits over time to the extent that different portions of the adult population contribute the successful progeny at different times (e.g. different years). Alternatively, if spawning locations are associated with 'subpopulations' that are temporally separated within the spawning season and are genetically distinct, then collections at the same location over time may be drawn from the distinct subpopulations. Thus, perceived temporal instability of genetic patterns may represent comparisons between sympatric subpopulations sharing the same spatially defined, but not temporally defined, spawning location.

Temporally distinct spawning (spring and autumn) of sympatric populations of Atlantic herring Clupea harengus has been proposed (e.g. in the northern and southern Gulf of St. Lawrence; McQuinn 1989, 1997). As such, the existence of sympatric subpopulations whose spawning times are separated by periods of 6 mo or less seems possible. 
Atlantic herring, Clupea harengus, are iteroparous, their spawning times are relatively predictable, and they are assumed to exhibit natal spawning-site fidelity (Sinclair \& Tremblay 1984). It has been suggested that herring spawn in temporally discrete cohorts (defined here as an assemblage of spawning fish) separated by several d to several wk (Ware \& Tanasichuk 1989). The coordinated cohort of spawners using the spawning ground at the same time has been called a 'spawning wave' (Hay 1985). Lambert (1984, 1987 and references therein) suggested that maximum landings of spawning herring in the northwest Atlantic coincide with the origin of measurably discrete larval assemblages and concluded that spawning groups (spawners associated with a particular location) segregate into spawning waves. The observations of discontinuous spawning (as inferred by variation in maturity stage) over time on spawning grounds (Stephenson et al. 2000) and discontinuities in the length distributions of larvae (Lambert 1987) are consistent with this suggestion and may reflect the existence of temporally separated sympatric subpopulations as hypothesized here.

In light of the inter-annual temporal genetic variation detected elsewhere in herring (Pacific herring, O'Connell et al. 1998; Atlantic herring, Kornfield et al. 1982, Kornfield \& Bogdanowicz 1987) and the documented observations of discrete spawning waves, we collected spawning herring on 2 occasions from each of 4 locations in the Scotian-Fundy region of the northwest Atlantic and used microsatellite markers to test for the existence of genetically distinct spawning waves.

Materials and methods. Tissue samples (blood or muscle) from spawning-stage herring were collected on 2 occasions from 4 annually occupied spawning locations in the waters surrounding Nova Scotia in 1998: German Bank (GB), Devastation Shoal (DS), Trinity Ledge (TL), and Scot's Bay (SB) (Fig. 1). Estimates of biomass ranged from $\sim 15 \times 10^{3}$ tonnes (Devastation Shoal) to $\sim 450 \times 10^{3}$ tonnes (German Bank) in 1999 (Stephenson et al. 2000). Intervals between the collections ranged between 6 and $15 \mathrm{~d}$ (Table 1) and collections from each location were assumed to be a random representation of the fish on the spawning ground that were susceptible to the equipment used to sample them (in this case, a purse seine). Length measurements, sex determination, maturity stage and year-class information (age determined using number of otolith annuli) for all individuals were provided by St. Andrews Biological Station, Department of Fisheries and Oceans.

DNA was isolated using Qiagen DNeasy genomic DNA extraction methods. Nine microsatellite loci (Cha1027, Cha1020, Cha1059, Cha1202, Cha1017, Cha1045, Cpa108, Cpa113, and Cpa102) were ampli-

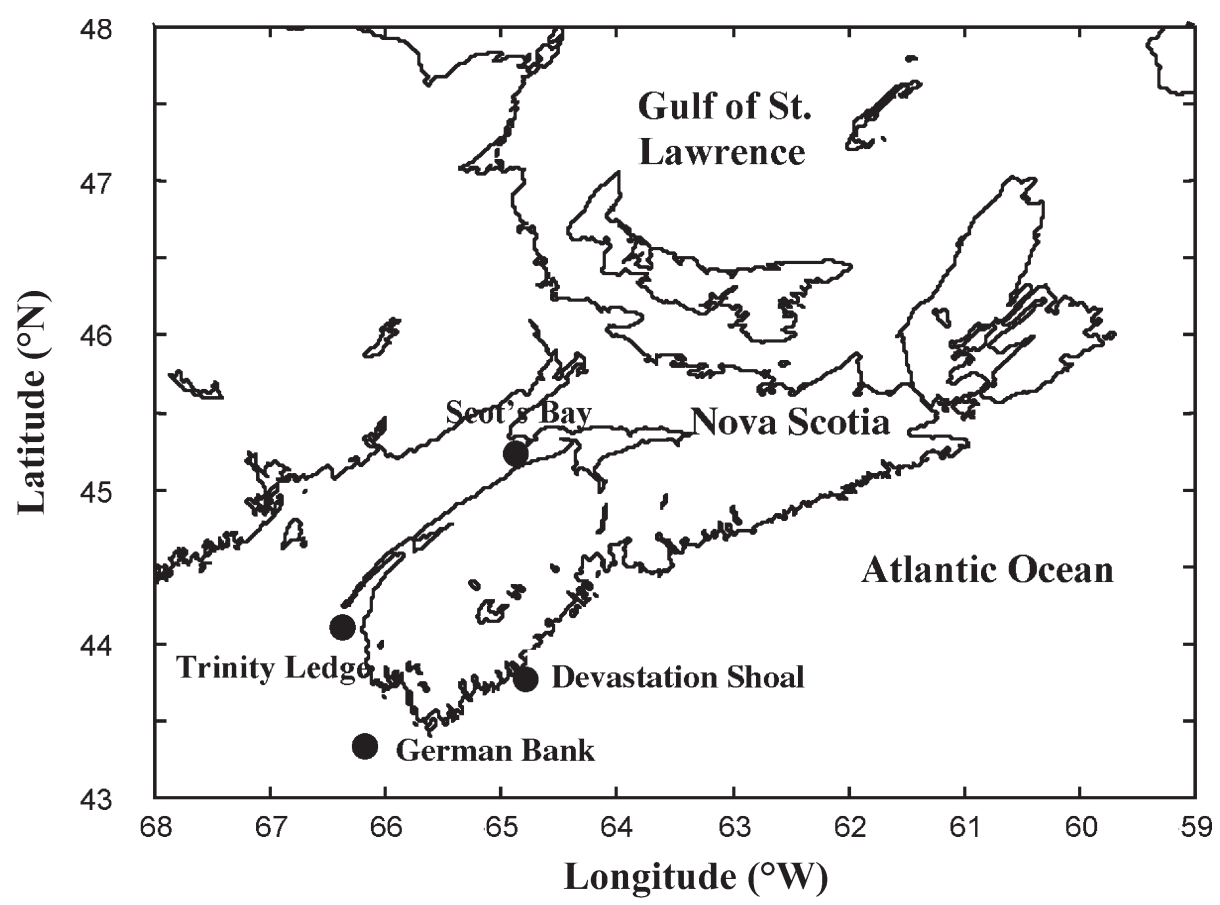

Fig. 1. Clupea harengus. Chart of spawning grounds (•) on the Scotian Shelf where Atlantic herring samples were collected from putative spawning waves in 1998 
fied, using polymerase chain reaction (PCR) for all samples. PCR amplification and electrophoresis conditions are given in McPherson et al. (2001a) and Olsen et al. (2002). DNA fragments were visualized and sized using an FMBIO II fluorescent imaging system (Hitachi).

Departures from Hardy Weinberg Equilibrium (HWE) were tested for each locus and collection using GENEPOP (Raymond \& Rousset 1995); p-values for each comparison were estimated using the Markov chain method with 2000 dememorizations, 200 batches and 2000 iterations per batch for each test. Pair-wise $F_{\text {ST }}$ estimates between collections (Wright 1951, as amended by Weir \& Cockerham 1984) were calculated using Genetix (Belkhir 2000), and 1000 permutations were used to estimate the probability of departure from the null hypothesis of genetic homogeneity. $F_{\mathrm{ST}}$ estimates were used to compare temporal and spatial genetic variation among collections and to generate the genetic dissimilarities used for multidimensional scaling (MDS; NCSS97, Hintze 1998). Average Identity (the expected proportion of loci that would be homozygous in the offspring of each pair of individuals) was estimated for each collection and recalculated with collections pooled by sample location (using Identix; Belkhir et al. 2002).

Linear regression techniques were used to test the null hypothesis of no linear relationship between the degree of differentiation between collections from the same location (as measured by $F_{\mathrm{ST}}$ ) and the time interval between collections. We also employed Exact tests (GENEPOP: Raymond \& Rousset 1995) to assess the statistical significance of allele frequency differences at individual loci between pairs of sample locations.
The p-values were calculated using a Markov chain method, as described above. Sequential Bonferroni procedures were used to adjust the critical significance value in multiple tests.

Results. Significant deviations (post-sequential Bonferroni) from HWE were observed in 3 of the $72(4.2 \%)$ single locus tests within spawning wave collections (Table 2) from each location. When spawning waves were pooled by location and tested for deviations from HWE, 2 of 36 (5.6\%) significant deviations were detected.

A significant difference $\left(F_{\mathrm{ST}}=0.0058, \mathrm{p}=0.001\right)$ was observed between the 2 Devastation Shoal spawning collections separated by $6 \mathrm{~d}$ (Table 1). The difference between the 2 Scot's Bay collections separated by $8 \mathrm{~d}$ was smaller and marginal $\left(F_{\mathrm{ST}}=0.003, \mathrm{p}=0.034\right)$. Only the Devastation Shoal comparison remained significant after sequential Bonferroni adjustments for multiple tests. No differences (based on $F_{\mathrm{ST}}$ estimates) were detected between either of the German Bank collections (14 d interval) or the Trinity Ledge collections (15 d interval). However, $F_{\mathrm{ST}}$ estimates between first and second collections at each location decreased as the time interval between collections increased $\left(\mathrm{r}^{2}=\right.$ $0.928, \mathrm{p}=0.03, \mathrm{n}=4$ ). Multidimensional scaling of pairwise $F_{\mathrm{ST}}$ estimates illustrates the genetic affinities of the spawning collections and demonstrates that the Devastation Shoal samples lie at 1 extreme of each dimension (Fig. 2).

Average Identity within each collection was greater than or equal to average Identity calculated when sample collections were pooled by location (i.e. average pair-wise Identity for Devastation Shoal samples were 0.205 and 0.208 for the first and second collec-

Table 1. Clupea harengus. Date of collection ( $\mathrm{yr} / \mathrm{mo} / \mathrm{d})$; number of herring sampled $(\mathrm{N})$; ages of fish within each collection $(\mathrm{Yr}$ range) at Devastation Shoal (DS), Scot's Bay (SB), German Bank (GB); and Trinity Ledge (TL). Mean pair-wise Identity estimates (PI) are calculated for each spawning wave collection and recalculated for collections pooled by location. Numbers 1 and 2 refer to the first and second collections in each location. Pair-wise $F_{\mathrm{ST}}$ estimates, above diagonal; associated p-values, below diagonal $\left(F_{\mathrm{ST}}\right.$ estimates significant after Bonferroni adjustments are given in bold)

\begin{tabular}{|c|c|c|c|c|c|c|c|c|}
\hline & DS1 & DS2 & SB1 & SB2 & GB1 & GB2 & TL1 & TL2 \\
\hline Date & $98 / 10 / 07$ & $98 / 10 / 13$ & $98 / 07 / 30$ & $98 / 08 / 08$ & 98/08/19 & $98 / 09 / 02$ & $98 / 08 / 27$ & $98 / 09 / 13$ \\
\hline $\mathrm{N}$ & 65 & 67 & 50 & 70 & 73 & 75 & 75 & 75 \\
\hline Yr range & $4-6$ & $4-6$ & $4-6$ & $3-7$ & $4-9$ & $4-9$ & $3-9$ & $3-6$ \\
\hline Pair-wise Identity (PI) & 0.205 & 0.208 & 0.193 & 0.195 & 0.189 & 0.188 & 0.190 & 0.185 \\
\hline Pooled PI & 0.183 & & 0.191 & & 0.188 & & 0.184 & \\
\hline DS1 & & 0.0058 & 0.0049 & 0.0017 & 0.0002 & 0.0002 & 0 & 0.0002 \\
\hline DS2 & 0.001 & & 0.0104 & 0.0030 & 0.0050 & 0.0026 & 0.0019 & 0.0015 \\
\hline SB1 & 0.008 & $<0.001$ & & 0.0029 & 0.0012 & 0.0041 & 0.0057 & 0.0024 \\
\hline SB2 & 0.110 & 0.029 & 0.034 & & 0.0002 & 0.0007 & 0.0011 & 0 \\
\hline GB1 & 0.380 & 0.002 & 0.177 & 0.406 & & 0 & 0.0007 & 0 \\
\hline GB2 & 0.394 & 0.044 & 0.004 & 0.293 & 0.784 & & 0.0005 & 0 \\
\hline TL1 & 0.513 & 0.060 & 0.002 & 0.173 & 0.278 & 0.313 & & 0 \\
\hline TL2 & 0.397 & 0.151 & 0.062 & 0.554 & 0.706 & 0.648 & 0.548 & \\
\hline
\end{tabular}


Table 2. Clupea harengus. Single locus statistics for sequential spawning collections of herring showing sample size (N), observed heterozygosity $\left(H_{0}\right)$ and number of alleles at each locus. Significant (after sequential Bonferroni) deviations from HWE are given in bold. ${ }^{* * *}$ Significant deviation from HWE when spawning collections are pooled by location

\begin{tabular}{|c|c|c|c|c|c|c|c|c|c|c|}
\hline \multirow{2}{*}{ Sample } & \multirow[t]{2}{*}{$\mathrm{N}$} & \multicolumn{9}{|c|}{ _ Locus (no. of alleles) } \\
\hline & & $\begin{array}{c}1027 \\
(31)\end{array}$ & $\begin{array}{c}1202 \\
(16)\end{array}$ & $\begin{array}{c}1059 \\
(21)\end{array}$ & $\begin{array}{c}1017 \\
(19)\end{array}$ & $\begin{array}{c}1020 \\
(30)\end{array}$ & $\begin{array}{c}1045 \\
(36)\end{array}$ & $\begin{array}{l}113 \\
(24)\end{array}$ & $\begin{array}{l}102 \\
(60)\end{array}$ & $\begin{array}{l}108 \\
(11)\end{array}$ \\
\hline DS1 & 62 & 0.935 & 0.729 & 0.774 & 0.903 & 0.918 & 0.807 & 0.907 & 0.887 & 0.617 \\
\hline $\begin{array}{l}\text { DS2 } \\
\text { Pooled DS }\end{array}$ & 65 & 0.918 & 0.661 & 0.693 & 0.813 & $\underset{* * *}{0.898}$ & 0.869 & 0.892 & 0.923 & 0.295 \\
\hline SB1 & 50 & 0.980 & 0.900 & 0.660 & 0.820 & 0.980 & 0.898 & 0.920 & 0.940 & 0.489 \\
\hline $\begin{array}{l}\text { SB2 } \\
\text { Pooled SB }\end{array}$ & 70 & 0.905 & 0.731 & 0.609 & 0.831 & 0.921 & 0.745 & 0.953 & 0.938 & 0.530 \\
\hline GB1 & 73 & 0.877 & 0.721 & 0.704 & 0.775 & 0.849 & 0.843 & 0.942 & 0.945 & 0.548 \\
\hline $\begin{array}{l}\text { GB2 } \\
\text { Pooled GB }\end{array}$ & 75 & 0905 & 0.662 & 0.707 & 0.795 & 0.893 & 0.849 & 0.931 & 0.930 & 0.534 \\
\hline TL1 & 75 & 0.945 & 0.708 & 0.770 & 0.775 & 0.932 & 0.878 & 0.960 & 0.927 & 0.486 \\
\hline TL2 & 75 & 0.920 & 0.693 & 0.671 & 0.730 & 0.917 & 0.861 & 0.919 & 0.986 & 0.528 \\
\hline Pooled TL & & & & & ${ }^{* * *}$ & & & & & \\
\hline
\end{tabular}

tions respectively, relative to 0.183 when the first and second collections were pooled and the average pairwise Identity was recalculated, Table 1).

Single locus comparisons within locations revealed a difference at Cha1027 ( $\mathrm{p}=0.0005)$ between the Devastation Shoal collections.

Discussion. The results demonstrate little genetic variation between what were assumed to be spawning waves of Atlantic herring on 3 of the 4 spawning grounds examined in the vicinity of Nova Scotia. However, a genetic difference was revealed at a subannual scale (d) at Devastation Shoal. Although the spawningwave phenomenon has been recognized in herring for

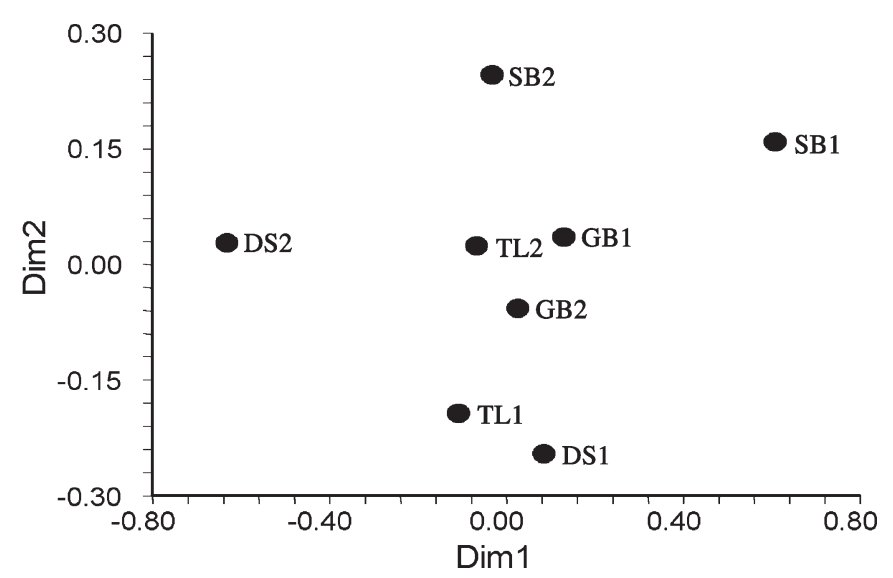

Fig. 2. Clupea harengus. Multi-dimensional scaling of pairwise $F_{\mathrm{ST}}$ among collections from Devastation Shoal (DS) Trinity Ledge (TL), Scot's Bay (SB), and German Bank (GB). Numbers 1 and 2 refer to the first and second spawning collections, respectively. Dimension 1 (Dim1) $r=0.63$, stress 0.14 Dimension $2(\mathrm{Dim} 2) \mathrm{r}=0.07$, stress 0.05 decades, few documented observations exist (but see Lambert 1984 for northwest Atlantic herring) and the potential for genetic variability among waves within the spawning season has not, to our knowledge, been explored until now.

Deviations from HWE were observed both within individual collections of spawning herring and when herring collections were pooled by location (Table 2). In all cases, single locus deviations differed from those detected in McPherson et al. (2001b) and are therefore unlikely the result of null alleles. Pooling of sample collections by location increased the number of significant deviations from HW expectations by $1.4 \%$. This may have been due to the resulting increase in statistical power provided by larger sample sizes, or may reflect some degree of genetic differentiation (e.g. Wahlund effect) between spawning wave collections at each (or a number of) locations. For example, in the Devastation Shoal analyses, 1 locus deviated from HWE when the 2 spawning wave collections were combined, but the same was not true when the spawning wave collections were considered separately.

Differences (based on $F_{\mathrm{ST}}$ ) between collections from the same location were observed in 2 of the 4 multilocus comparisons: (1) marginal differences between the 2 Scot's Bay collections; and (2) differences, significant after sequential corrections for multiple tests, between the 2 Devastation Shoal collections. In addition, 1 single locus Exact test result remained significant following sequential corrections for multiple tests; Cha1027 in the comparison between Devastation Shoal samples. Multidimensional scaling (Fig. 2) of $F_{\mathrm{ST}}$ among spawning collections illustrates the spatial and temporal pattern of genetic differentiation among samples and thus (potentially) genetic evidence of spawn- 
ing waves. It seems reasonable to suggest, at a minimum, that these data are consistent with temporal stability (with respect to genetic variation) among collections at German Bank and Trinity Ledge. As the genetic difference between the Scot's Bay samples is marginal, after corrections for multiple tests, it too may be interpreted as illustrating temporal stability. However, the existence of temporally separated and genetically distinct subpopulations cannot be refuted in these locations due to the limited sampling (e.g. sampling was not continued throughout the entire spawning season).

The significant genetic difference between Devastation Shoal collections cannot easily be attributed to improper sampling as collections were made up of >50 individuals, all in spawning condition, and all collected on the spawning ground. Furthermore, Hay (1985) reported that the largest and oldest herring tend to dominate spawning in the first wave and the smaller fish increase in frequency in subsequent waves. Our data are entirely consistent with Hay's findings for all locations other than Devastation Shoal (Table 1) where $>80 \%$ of the individuals in both spawning collections were from the same 1992 yearclass. Therefore, the 1992 year-class from each of the 2 Devastation Shoal collections were compared, providing a direct assessment of temporal stability within a year-class and between putative spawning waves. As reported in McPherson et al. (2001b), a difference was detected $\left(F_{\mathrm{ST}}=0.0043, \mathrm{p}=0.013\right)$ and because this year-class was compared directly at Devastation Shoal, the result is not easily attributed to unequal year-class representation (in concert with a high degree of reproductive variance) or sampling bias. Although Kornfield et al. (1982) doubted that intergenerational differences could contribute significantly to population differentiation (due to the presence of overlapping generations in the collections) because herring are iteroparous, McPherson (2002) demonstrated a discrepancy between results generated using sample collections grouped by year-class, as opposed to collections comprising year-classes pooled (the demonstrable norm in population genetic studies). Thus, we can tentatively conclude that spawning waves were in fact sampled at Devastation Shoal and that the differences detected reflect the genetic differentiation of the spawning waves (or sympatric subpopulations). At the other locations, spawning waves (and differences between them) may have existed but were not detected because (1) they were not adequately sampled, or (2) multiple year-classes were pooled within sample collections thereby masking among-wave genetic variation. Unfortunately (and unlike the Devastation Shoal collections which predominantly comprised the same year-class), direct year class comparisons could not be made within the other locations due to sample size constraints.

If the genetic differentiation detected between Devastation Shoal samples of the same year-class is the result of differential survival, then the level of relatedness among individuals within a collection from each location can be compared to the level of relatedness estimated when collections are pooled by location. Such a comparison allows us to assess which scenario better approximates panmixia (associated with a lower estimate of Identity). In all cases (Table 1), average Identity estimates of spawning collections were greater than or equal to average Identity estimates when spawning collections were pooled by location. This suggests a higher degree of relatedness within the individual spawning collections (when compared to collections pooled by location) and is consistent with some degree of genetic affinity within spawning waves (or sympatric subpopulations) at locations other than Devastation Shoal.

Although limited by a small sample size, and contrary to what might have been predicted, an inverse relationship was found between the time interval separating first and second spawning collections and the pair-wise $F_{\mathrm{ST}}$ estimates. In particular, the Devastation Shoal collections were separated by only $6 \mathrm{~d}$ (the shortest interval between all waves in the collections) and were found to be the most different. Although we cannot suggest a biologically meaningful explanation for this result, we can conclude that a rapid $(<6 \mathrm{~d})$ turnover of fish on this spawning ground likely occurred.

In further contrast to Hay's (1985) observations, herring from the 1992 year-class in the second wave at Devastation Shoal were significantly larger (McPherson et al. 2001a) than herring from the 1992 year-class in the first spawning wave ( $t$-test, $\mathrm{p}<0.001)$. This is also consistent with the suggestion of a rapid population turnover on the spawning ground. The $6 \mathrm{~d}$ estimate of replacement period is similar in magnitude to the shortest $(8 \mathrm{~d})$ estimates of residence time, calculated by Lambert (1984) using length differences among larval cohort distributions.

It is clear from the literature that reliable estimates of residence time of herring on their respective spawning grounds are limited. Yet such estimates would seem to be essential for effective resource management. Estimates of spawning biomass (generated using hydroacoustic techniques) over the spawning period (using a fixed residence time estimate) are often (e.g. in NAFO [North Atlantic Fisheries Organisation] Divisions $4 \mathrm{WX}$ ) used to infer population size for which exploitation limits are set for each spawning ground (Stephenson et al. 1999). Thus, if the residence time varies across the spawning locations or deviates from the estimate used, or both, then faulty 
biomass estimates and risk-prone exploitation rates may result.

Although few differences were observed within 3 of 4 pairs of collections, herring collected $6 \mathrm{~d}$ apart and within a few $\mathrm{km}$ of each other on Devastation Shoal showed clear genetic and morphometric differences, including within year-class. Thus, distinct sympatric subpopulations may exist (ephemerally or otherwise) and potentially reflect the spawning wave phenomenon. Sampling strategies executed in the absence of this knowledge may be responsible for generating temporal instability reported for herring. With the data in hand, we suggest that the differences in Devastation Shoal herring may either: (1) reflect the existence of temporal (as well as spatial) substructure in herring as suggested by Smedbol \& Stephenson (2001) and demonstrated by the presence of distinct Devastation Shoal subpopulations/spawning waves that are temporally separated by $6 \mathrm{~d}$ or less; or (2) reflect sub-annual temporal genetic patchiness for which we cannot attribute a mechanism but which may involve nonrandom sampling; or (3) reflect a transient use of a spawning ground by a different population of herring, in which case the assumption of natal spawning site fidelity often assumed for herring would be invalid. If, however, another population was using Devastation Shoal as a spawning ground, we would have predicted that the source population for the second Devastation Shoal collection be from the most geographically proximate location considered; but only the Trinity Ledge collections showed genetic affinity to the second Devastation Shoal collection $\left(\right.$ Table $1 ; F_{\mathrm{ST}}=0.0015$ and $F_{\mathrm{ST}}=0.0019, \mathrm{p}>0.1$ for first and second spawning waves, respectively).

Synchronized sample collections (virtually simultaneous collections from the same location) and continuous sampling over the complete spawning season at the spawning grounds is essential (though logistically challenging) if the degree of genetic variability attributable to improper sampling or random chaotic patchiness at this small temporal scale is to be quantified.

Acknowledgements. Thanks to M. Power, J. Fife, G. Melvin, and many commercial fishers for their assistance in securing samples. We thank K. Spence for laboratory assistance, J. Seeb and J. Olson for providing Pacific herring loci prior to publication, P. Smouse and 3 anonymous reviewers for insightful comments that improved the manuscript. This work was supported through Canadian Biotechnology Strategy funding to C.T.T. and E. L. Kenchington, and NSERC PGSs to AAM.

\section{LITERATURE CITED}

Belkhir K (2000) GENETIX, logiciel sous Windows pour la génétique des populations. Laboratoire Génome et Popu- lations, CNRS UPR 9060, Université de Montpellier II, Montpellier

Belkhir K, Castric V, Bonhomme F (2002) Indentix, a software to test for relatedness in a population using permutation methods. Mol Ecol Notes 2:611-614

Chapman RW, Sedberry GR, McGovern JC (1999) The genetic consequences of reproductive variance: studies of species with different longevities. Am Fish Soc Symp 23:169-181

David P, Perdieu MA, Pernot AF, Jarne P (1997) Fine grained spatial and temporal population genetic structure in the marine bivalve Spisula ovalis. Evolution 51: $1318-1322$

Hay DE (1985) Reproductive biology of Pacific herring (Clupea harengus pallasi). Can J Fish Aquat Sci 42(Suppl 1): 111-126

Hedgecock D (1994) Does variance in reproductive success limit effective population sizes of marine organisms? In: Beaumont A (ed) Genetics and evolution of aquatic organisms. Chapman and Hall, London, p 122-134

Hintze J (1998) Number cruncher statistical software. Version 6. NCSS Statistical Software, Kaysville, Utah

Johnson MS, Black R (1982) Chaotic patchiness in an intertidal limpet, Siphonaria sp. Mar Biol 70:157-164

Kornfield I, Bogdanowicz S (1987) Differentiation of mitochondrial DNA in Atlantic herring, Clupea harengus. Fish Bull 85:561-568

Kornfield I, Sidell B, Gagnon P (1982) Stock definition in Atlantic herring (Clupea harengus): genetic evidence for discrete fall and spring spawning populations. Can J Fish Aquat Sci 39:1610-1621

Lambert T (1984) Larval cohort succession in herring (Clupea harengus) and capelin (Mallotus villosus). Can J Fish Aquat Sci 41:1552-1564

Lambert T (1987) Duration and intensity of spawning in herring Clupea harengus as related to the age structure of the mature population. Mar Ecol Prog Ser 39:209-220

Larson RJ, Julian RM (1999) Spatial and temporal genetic patchiness in marine populations and their implications for fisheries management. CalCOFI Report 40:94-99

McPherson AA (2002) Patterns of genetic variation on ScotiaFundy Atlantic herring. PhD thesis, Dalhousie University, Halifax, Nova Scotia

McPherson AA, O'Reilly PT, McParland T, Jones MW, Bentzen P (2001a) Isolation of nine novel tetranucleotide microsatellites in Atlantic herring (Clupea harengus). Mol Ecol Notes 1:31-32

McPherson AA, Stephenson R, O'Reilly PT, Jones MW, Taggart CT (2001b) Genetic diversity of coastal northwest Atlantic herring: implications for management. J Fish Biol 59(a):356-370

McQuinn I (1989) Identification of spring- and autumn spawning herring (Clupea harengus harengus) using maturity stages assigned from a gonadosomatic index model. Can J Fish Aquat Sci 46:969-980

McQuinn I (1997) Year-class twinning in sympatric seasonal spawning populations of Atlantic herring, Clupea harengus. Fish Bull 95:126-136

O'Connell M, Dillon M, Wright J, Bentzen P, Merkouris S, Seeb J (1998) Genetic structuring among Alaskan Pacific herring (Clupea pallasi) populations identified using microsatellite variability. J Fish Biol 53:150-163

Olsen JB, Lewis CJ, Kretschumer EJ, Wilson SL, Seeb JE (2002) Characterization of fourteen tetranucleotide microsatellite loci derived from Pacific herring. Mol Ecol Notes 2:101-103

Purcell MK, Kornfield I, Fogarty MJ, Parker A (1996) Inter- 
decadal heterogeneity of mitochondrial DNA in Atlantic haddock, Melanogrammus aeglefinus, from Georges Bank. Mol Mar Biol Biotech 5:185-192

Raymond M, Rousset F (1995) GENEPOP (version 1.2): population genetics software for exact tests and ecumenicism. J Hered 86:248-249

Sinclair M, Tremblay M (1984) Timing of spawning on Atlantic herring (Clupea harengus harengus) populations and the match-mismatch theory. Can J Fish Aquat Sci 14: 1055-1065

Smedbol RK, Stephenson RL (2001) The importance of managing within-species diversity in modern fisheries. J Fish Biol 59a:109-128

Stephenson RL, Power MJ, Clark KJ, Melvin GD, Fife FJ,

Editorial responsibility: Simon Archer (Contributing Editor), Guildford, United Kingdom
Scheidl T, Waters CL, Arsenault S (2000) 2000 evaluation of $4 \mathrm{VWX}$ herring. Canadian Stock Assessment Secretariat Research Document 2000/065

Stephenson RL, Rodman K, Aldous D, Lane DE (1999) An inseason approach to management under uncertainty; a case of the SW Nova Scotia Herring Fishery. ICES J Mar Sci 56:1005-1013

Ware DM, Tanasichuck RW (1989) Biological basis of maturation and wave spawning in Pacific herring (Clupea harengus pallasi). Can J Fish Aquat Sci 46:1776-1784

Weir B, Cockerham C (1984) Estimating F-statistics for the analysis of population structure. Evolution 38:1358-1370

Wright S (1951) The genetical structure of populations. Ann Eugen 15:323-354

Submitted: July 29, 2002; Accepted: November 22, 2002 Proofs received from author(s): January 21, 2003 